\title{
Using Senior Project to improve Auto Insurance Course Teaching
}

\author{
Yali Yang ${ }^{1, a}$, Renhong Juan ${ }^{1, b}$, Hao Chen ${ }^{1, c,{ }^{*}}$ \\ ${ }^{1}$ College of Automotive Engineering, Shanghai University of Engineering Science, Shanghai, \\ 201620, China \\ aemail: carolyn71@163.com, bemail:ren-hongjuan@163.com, cemail:pschenhao@163.com \\ *Corresponding author
}

\section{Keywords: Auto Insurance; Teaching; Senior Project}

\begin{abstract}
Auto Insurance Course is a practice oriented course, with close relation with market and industry. Senior project is a platform for student to use their knowledge and develop their ability. Senor project is closely related with auto insurance course teaching, which can improve the teaching result of course. This paper investigated the correlation between senior project and auto insurance course to figure out a useful method to improve the course teaching. Based on characteristics analysis, correlation were emphasized on literature review and translation. Improving methods were proposed accordingly. As long as senior project and course teaching are integrated properly, result of both course teaching and senior project will be improved, thus to improve the student ability and benefit their future career.
\end{abstract}

\section{Introduction}

With the rapid development in economy, the auto population maintains rapid development in China. Consequently, the demand for auto insurance is growing as the same speed. In China, auto insurance is a big business and, like many other things in the country, it' s growing rapidly. Auto insurance premium constitutes about $70 \%$ of the overall premium in the Chinese general insurance market, and growth prospects remain promising due to surging car sales and the recent introduction of compulsory auto liability coverage. China automobile insurance industry is a major contributor in non life insurance segment. It is also regarded as having best rate of growth among all insurance industries of China[1].

Special talent in auto insurance and claim is required for the industry development, which requires combined knowledge and technique in auto insurance and auto industry.

However, the development of auto insurance industry is restricted due to the lack of specialized personnel. Under this circumstance, auto industry course is started in many colleges in China for auto industry related majors, to solve this problem.

Auto Insurance Course has combined knowledge with theory and practice, which cultivate students' ability in auto evaluation, auto testing, accident survey and loss assessment. Thus, this course combines many auto related contents and practice, which is quite hard to comprehend thoroughly. However, due to the characteristics of this course, the teaching is with high difficulty and the teaching result is not very good. Thus, this paper conducted teaching reform research on this course, to improve the teaching effect[2].

The capstone achievement in obtaining a bachelor's degree in Engineering is the senior project. The senior design experience is intended to be a culminating experience in college education as an engineer. Senior project plays an very important role, which is the combination of learned knowledge and practical problems. Senior project is the opportunity for students to utilize their knowledge to solve real problem, a practical training before working. In planning, designing, and executing design project, student will be expected to bring together disparate pieces of knowledge that he/she have gained throughout studies in college. It is critical to student to improve their ability in problem identification, planning, problem solving, which can acclimate him/her to the real working area rapidly. It is also a test for the ability of teaching, creativity cultivation of teachers[3,4].

For students in automotive engineering, especially in auto insurance and claim related areas, it is 
necessary to take advantage of senior project to utilize the course knowledge. Based on the relationship of auto insurance course course and senior project, this paper is proposed to find a good cooperation of course and senior project, to promote the teaching effect of Auto Insurance Course.

\section{Issues of auto insurance course teaching}

\section{Low teaching hours}

Usually, teaching hours for auto insurance course is 32 hours, which is far less adequate to maintain ideal teaching effect. Thus, teachers are not only the spreader for text information, but also instructor for learning method. Auto insurance course is more market oriented, which means students need more time to practice. The basic theory is not quite adequate for the student to qualify to the position of evaluator. Focus should be put on developing the ability of effective study and rational learning management. However, most of the teachers spend a lot of time just on basic theory, but not ability development, especially for practice. Consequently, students' initiative and interest for the course reduced, which deteriorates the status of this course.

Insufficient practice experience of teachers

This course is set up just for several years. Most of the teachers are not very experience in auto insurance and claims, especially practical experience. There are just few teacher included in real auto insurance and claims training and obtain corresponding vocational qualification. Due to the lack of real experience in auto insurance course, it causes obstacles for course teaching. Most teachers focus more on theory teaching, other than ability improvement and practical involvement, which reduce the pertinence and practical application of knowledge.

Even though case study method is using by some teachers. Due to the lack of practical experience, the cases are either download from Internet or from textbook. Teacher does not have real experience, which restricts the effect of case study. Active participation of student is hard to achieve[5].

\section{Rigid teaching method}

Traditional teaching method, characterized in dominated speaking and teaching by teachers. Students were passive receiver, not active participants in class, resulting in lower learning initiative, less thinking and feedback. Classroom teaching is made up of teaching and learning. It is a bilateral activity that teachers and students must join in together. It's form isn't monologue but dialogue[4].

Insufficient and inefficient practical teaching

Auto Insurance Course is more practical oriented, with strong requirement on practical teaching. However, the practical teaching is insufficient and inefficient. First, insufficient practice infrastructure results in shortage in practice base for related practice. Some colleges even do not have in-school base and stable outside base. Second, practice teaching method is few. The main method is one-way lecture on theory, which weak the operational ability and creativity of student. Third, weak management on practice teaching reduces teaching results. No systematic management on practice teaching was found in most colleges. Practice teaching is more related on student self-contact outside company without proper supervision and management. The existing practice bases are not well managed, with lower efficiency[6].

\section{Lacking of practice}

As a practice oriented course, the lacking of practice significantly affect the teaching result. Firstly, the relation of theory and practice is separated. The lacking of practice of students makes it hard for students to understand the basic theory thoroughly. Without practice, students do not know how to make use of what they have learned, which causes lots of waste on efforts. Secondly, lacking of practice restricts the improvement of ability for teachers. Only with harmony combination of theory and practice, can the effect of the course be better.

\section{Relationship between Auto insurance course and senior project}

Senior project includes basic theory and practical operation, which is a systematic using of knowledge. Student need to use their knowledge for a specific subject, sometime a real subject for 
the industry.

Firstly, a literature review is required in the selected area. Students in auto insurance and claim engineering or related have learn a lot of basic courses. Now students need to integrated them together, and also put their own thoughts in. This integration process will enhance the understanding of course teaching emphasis, thus to form a systematic knowledge of auto insurance course , which will be very valuable for students' future career.

Secondly, as a practice oriented course, senior project provides an ideal platform for students to use their knowledge and improve themselves in practice. The purpose for auto insurance course is to develop the ability of auto insurance course ability, thus the practical technical process should be included, such as auto damage, technical status and overall performance checking, loss assessment and so on. There are three major knowledge modules including in used car value evaluation, which requires a lot of practice to make them qualified to the market. By using all kinds of practical teaching methods, experimental teaching, on-site demonstration, case study and senior project to visualize their basic theory base on practice, therefore cultivate their actual practice ability on auto insurance course.

\section{Combining senior project to improve teaching of Auto insurance course}

\section{Using opening report writing to improve literature search, reading and summarization}

Opening report is an essential part of the senior project, which requires a lot of literature review in the specific project area. Students are required to search literature, reading and summarize the research content of the literature. This is an good utilization of learned knowledge, and also incorporating their own idea.

Thus, teacher should be aware the relation between this course and senior project. Besides the basic theory and knowledge, certain amount of time should be put in the literature reading, summarizing. The report writing technique should also be included. Some practices related to the above technique should be incorporating in course teaching. By this way, the starting time of senior project actually moves earlier. Students can be divided into groups with 3 to 4 person based on project subject. They can work together to finish the literature review. It can not only improve the ability in literature review, but also ability in cooperation, which will enhance the result of both course teaching result and senior project.

Using industry and market related senior project

The purpose for auto insurance course is to develop the ability of auto insurance and claim related knowledge and skill for future career. Therefore, teaching should be closely connected to market development. Beside the basic theory and structure, efforts should be put on market requirement. The teaching should emphasized on ability cultivation to meet the market requirement. The teaching should include the auto insurance and claim process, which includes application, testing and verifying, technical checking, evaluation, loss assessment and report submission. Thus, reporting ability should be included in the course. After basic theory teaching, case, video material and experiments should be included to force student to think and discuss in groups, with the summary and guidance of teachers, thus to improve their actual market ability[7].

A lot of senior projects are from auto companies, which are very valuable to the improvement of student's ability. Each senior project can be very prepared to specific issue. Student has to use their knowledge, take latest market and industry development status into consideration. This is the perfect platform, which matches with the goal of auto insurance course, thus to strengthen their knowledge and ability.

Senior project also can be thought as one kind of case study, which is real, not from textbook. Due to the character of auto insurance course, case study is one of the most important part. Market and industry oriented senior project can fit the requirement in both quantity and timing. In this kind of case study, student can not only understand the market, but also increase their learning interest thus to improve their analyzing ability for the future work[6]. Thus, to further improve the teaching result and promote the senior project, more actual case study should be include in, on the basis of fundamental theory teaching. This would help student to match the knowledge learning in course 
and practice in senior project.

Using senior project as a supplementary for course teaching

Currently, the teaching hour for the course is not enough for cover all the stuff. Senior project can be an useful supplementary for course teaching. Senior project in auto insurance course or related is the continuity of auto insurance course teaching. Student will use the learned knowledge, update to fit the market and industry requirement, which increase the student's horizon and also basic knowledge, and also form some extend of development. The proper use of senior project will do much benefit to student.

Therefore, the teaching of used car course should be emphasis on both fundamental theory and issue resolution techniques. Teachers are not only the spreader for text information, but also instructor for learning method. Focus should be put on developing the ability of effective study and rational learning management, which will benefit more in senior project[8].

\section{Conclusion}

Senor project is closely related with auto insurance teaching, which can improve the teaching result of course. This paper investigated the correlation between senior project and auto insurance course to figure out a useful method to improve the course teaching. Based on characteristics analysis, correlation were emphasized on literature review and translation. Improving methods were proposed accordingly. Senior project can be incorporated with course teaching, which can be used as the platform to improve student reporting and practice, and also a supplementary source for course teaching. Accordingly, auto insurance course teaching should be adjust to fit the senior project. As long as senior project and course teaching are integrated properly, result of both course teaching and senior project will be improved.

\section{Acknowledgement}

This work is sponsored by course developing project on Auto Insurance and Claim Course (k201206004) and Platform Developing Project of Modern Auto Service Engineering Major (XKCZ1214) in Shanghai University of Engineering Science.

\section{References}

[1] Jenny Lai and Hussain Ahmad. "Auto Insurance picks up speed in China," Emphasis,2007,3:2-5.

[2] Chen Qin. “Application of CaseMethod in the Auto Insurance Teaching,” Journal of Guangdong Industry Technical College, 2007,6(4):36-39.

[3] Heng. Z, Wen. B.C and Bo. J.J et al. Exploration of Reformation and Innovation of Graduation Project. Journal of Huaiyin Institute of Technology,2005, 14(2):71-72(2005).

[4] Yuxue Jin, Yiheng Wang, Yuhang Guo. Specialized course teaching methods for engineering in college. China Education Innovation Herald. 2008,29:143-144.

[5] Robinson, Marc."How to write a case study,” William Davidson Institute note 1-429-140, Rev.

October 10, 2010.

[6] F.M. Guan, C.W. Zheng. "Course development and teaching reform based on process for automotive marketing major,” Teaching Research, 2010,2:15-18

[7 Dong E.G, Zhang L., Guan Z.W., et al. "Reform and practice of Auto Insurance and Claim Course,” Specialized Education Research, 2010,11:82-83.

Song X.Q. "Research on the teaching mode of Auto Insurance and Claim Course in college,” Educaiton and Teaching, 2011,12:94-95. 